\title{
Diagnóstico socioeconômico da produção leiteira em três assentamentos de reforma agrária no semiárido do Estado de Sergipe
}

\section{Socioeconomic diagnosis of milk production in three agrarian reform settlements in the semiarid of Sergipe State}

\author{
Aline Guimarães de Oliveira ${ }^{1 *}$; Veronaldo Souza de Oliveira ${ }^{2}$; \\ Gladston Rafael de Arruda Santos ${ }^{2}$; Angela Cristina Dias Ferreira²; \\ Givaldo Silva Santos ${ }^{3}$; Eder Pollykarton Teixeira de Lima ${ }^{3}$; \\ Diomar Cláudio dos Santos Sobrinho후 Camila Thiara Gomes Carvalho ${ }^{1}$
}

Resumo

Foi realizado um levantamento socioeconômico da pecuária leiteira, no período de novembro de 2007 a Janeiro de 2008, nos assentamentos de reforma agrária Paulo Freire, Cachoeirinha e Cajueiro, localizados nos municípios sergipanos de Porto da Folha, Gararu e Poço Redondo. Os dados foram obtidos por meio da aplicação de questionários aos produtores, contendo perguntas abertas que abordaram questões relacionadas desde o fator social ao econômico. Foi observado alto índice de analfabetismo entre os produtores dos assentamentos pesquisados (variando de 28,5 a $49 \%$ ), o qual interfere negativamente no sistema de produção devido a sua dificuldade em entender e aplicar novas tecnologias. O rebanho era caracterizado por animais mestiços provenientes de cruzamentos entre Holandês e Gir ou Guzerá e pequena produção média diária (de 5,4 a 6,5 litros/vaca), com redução na lucratividade e comprometimento da renda familiar. Percebeu-se relação desfavorável entre o valor recebido por litro de leite - variando de $\mathrm{R} \$ 0,52$ a $\mathrm{R} \$ 0,54$, entre os assentamentos - e o custo médio de produção de um litro de leite, variando de $\mathrm{R} \$ 1,19$ a $\mathrm{R} \$ 1,44$. Além disso, a dificuldade de acesso à tecnologia e assistência técnica foram problemas encontrados em 23,8; 90 e 84,8\%, respectivamente, nos assentamentos Paulo Freire, Cachoeirinha e Cajueiro. Dessa forma, é necessário o fomento de pesquisas e alternativas para melhorar a produtividade e a sustentabilidade de produtores com essas condições de criação e que o Movimento dos Trabalhadores Rurais Sem Terra (MST) invista principalmente em assistência técnica e educação aos assentados para que se promova uma aceleração e melhoria no seu desenvolvimento.

Palavras-chave: Agricultura familiar, assistência técnica, rebanho leiteiro

\begin{abstract}
The aimed this research was a socioeconomic survey of dairy farms, from November 2007 to January 2008, in agrarian reform settlements Paulo Freire, Cachoeirinha e Cajueiro, located respectively in municipalities Porto da Folha, Gararu e Poço Redondo in the semiarid of Sergipe State. Data were
\end{abstract}

\footnotetext{
${ }^{1}$ Discentes de Mestrado em Zootecnia, Universidade Federal de Sergipe, UFS, São-Cristóvão, SE. E-mail: alinegzoo@yahoo.com. br; diovet@ig.com; camila thiara@hotmail.com

${ }^{2}$ Profs. Drs. do Dept ${ }^{\circ}$ de Zootecnia. UFS, São-Cristóvão, SE. E-mail: veronaldo@terra.com.br; gladstonrafael@ufs.br; acrisdias@ ufs.br

${ }^{3}$ Discentes de Graduação em Engenharia Agronômica. UFS, São-Cristóvão, SE. E-mail: givaldoagro@hotmail.com; eder_ teixeiralima@hotmail.com
}

* Autor para correspondência 
obtained through questionnaires to producers, containing questions that dealt from the social to the economic factor. Was observed a high rate of illiteracy among producers (varying from 28.5 to $49 \%$ ), which prejudice the production system due to their incapacity to understand and apply new technologies. The herd was characterized by crossbred animals derived from crosses between Holstein and Gir or Guzera and small production daily (5.4 to 6.5 liters/cow), with reduction in profitability and commitment of family lace. It was perceived unfavorable relationship between the amount received per liter of milk - varying from $R \$ 0.52$ to $R \$ 0.54$, between the settlements - and the average cost of producing a liter of milk, varying from $\mathrm{R} \$ 1.19$ to $\mathrm{R} \$ 1.44$. Moreover, the difficulty of access to technology and technical assistance are problems found in 23.8, 90 and $84.8 \%$, respectively, in the settlements Paulo Freire, Cachoeirinha and Cajueiro. Therefore, is necessary the fomentation of research and development of alternatives to improve the productivity and sustainability of producers with these breeding conditions and the Movement of Landless Rural Workers (MST) invests mainly technical assistance and education to the settlers to that be promoted an acceleration and improvement in its development.

Key words: Dairy herd, family agriculture, technical assistance

\section{Introdução}

A indústria de laticínios brasileira vem experimentando anualmente um crescimento substancial na produção de leite. De 2000 a 2010, a produção leiteira nacional passou de 19,76 para 30,71 bilhões de litros ao ano, segundo dados do Instituto Brasileiro de Geografia e Estatística (IBGE, 2010). O Nordeste tem acompanhado esse desempenho, apresentando uma participação de $12,4 \%$ na produção total, sendo que o Estado de Sergipe obteve uma produção de 296,6 milhões de litros de leite, ocupando $17^{\mathrm{a}}$ posição como maior Estado produtor, representando $1 \%$ da produção leiteira nacional.

Na região semiárida do Estado de Sergipe, a produção de leite está ligada a agricultura familiar realizada por pequenos produtores. De acordo com dados do Ministério de Desenvolvimento Agrário (MDA, 2012), o Estado de Sergipe apresenta 214 projetos de assentamentos distribuídos em uma área de 181.195 ha. e 9779 famílias assentadas, sendo que os municípios de Nossa Senhora da Glória, Porto da Folha, Poço Redondo, Gararu, Canindé do São Francisco e Monte Alegre apresentam um bom número de assentamentos de reforma agrária - 96 ou $44 \%$ do total de assentamentos sergipanos - que exploram a pecuária leiteira principalmente por estarem incluídos na região considerada bacia leiteira de Estado de Sergipe. Porém até o momento, não foi identificado nenhum trabalho referente a diagnósticos socioeconômico da produção de leite, problemas relacionados à comercialização dos produtos, qualidade do leite, nutrição e sanidade dos animais no Estado de Sergipe.

Para conhecer a realidade das propriedades rurais e encontrar subsídios para gerar e transferir tecnologias compatíveis com esta realidade torna-se necessário o conhecimento do perfil das mesmas. (FERNANDES; LIMA, 1991). As regiões semiáridas são regiões leiteiras que apresentam escassez de informações relacionada aos índices de produção e de manejo nutritivo, reprodutivo e sanitário adotados pelos produtores, pesquisas que visam à caracterização da produção, constituem uma importante ferramenta para pesquisas de novas alternativas produtivas, bem como para orientar programas de assistência a agricultores familiares (LEITE et al., 2004; SANTOS; AZEVEDO, 2009).

O objetivo deste trabalho foi realizar um levantamento socioeconômico da pecuária leiteira em três assentamentos de reforma agrária localizados na região semiárida do Estado de Sergipe.

\section{Material e Métodos}

O presente trabalho foi desenvolvido nos assentamentos de reforma agrária Paulo Freire, Cachoeirinha e Cajueiro, ligados ao Movimento dos Trabalhadores Rurais sem Terra (MST) e localizados nos municípios de Porto da Folha, Gararu e Poço 
Redondo, respectivamente, no Estado de Sergipe. O tipo climático segundo a classificação de Köppen é caracterizado como BSh (árido, seco e quente). A precipitação pluviométrica média é de $500 \mathrm{~mm} / \mathrm{ano}$ e apresenta valores inferiores a $30 \mathrm{~mm}$ nos meses de verão; a temperatura média anual é de $26{ }^{\circ} \mathrm{C}$, sendo a temperatura mínima média em torno de $20^{\circ} \mathrm{C}$ e a máxima média de $32{ }^{\circ} \mathrm{C}$ (SIRHSE, 2010).

O levantamento dos dados foi feito por meio da aplicação de questionários aos produtores de leite de cada assentamento entre os meses de novembro de 2007 e janeiro de 2008. A aplicação dos questionários foi feita por estudantes previamente treinados do curso de Engenharia agronômica da Universidade Federal de Sergipe (UFS). O questionário foi adaptado do Diagnóstico socioeconômico das Bacias Leiteiras de Parnaíba - PI e Teresina - PI (SEBRAE/PI, 2005) para as condições dos assentamentos estudados.

Para determinar o tamanho da amostra de pesquisa, foi realizado um levantamento para se obter o universo dos produtores de leite de determinado assentamento. No caso dos assentamentos Cachoeirinha e Cajueiro, o universo foi de 44 produtores de leite por assentamento, levando-se em consideração aqueles que possuíssem no mínimo cinco vacas em lactação. Já para o assentamento Paulo Freire, este universo foi de 40 produtores, adotando-se o mesmo critério do número mínimo de vacas em lactação.

Foram realizadas várias visitas às áreas dos assentamentos para aplicação dos questionários ao proprietário ou responsável pelo rebanho. O roteiro da entrevista foi elaborado com perguntas abertas que abordaram questões visando à caracterização do produtor, da propriedade, da sanidade e alimentação dos animais, da produção, distribuição e comercialização do leite.

Ao término da aplicação dos questionários, o número de famílias entrevistadas para os assentamentos Cachoeirinha e Cajueiro foi de 33 produtores, correspondendo a $75 \%$ do total dos 44 produtores de leite. No assentamento Paulo Freire, dos 40 proprietários entrevistados, 21 foram selecionados, totalizando um percentual de $75 \%$. Devido ao tipo de pesquisa, os resultados das entrevistas foram organizados e apresentados de forma descritiva em termos de percentuais.

\section{Resultados e Discussão}

\section{Grau de escolaridade}

Como pode ser observado na Tabela 1, com relação ao nível de escolaridade, os percentuais de analfabetos dos assentamentos Paulo Freire, Cachoeirinha e Cajueiro estão acima da média nacional de 10\% (IBGE, 2009). Observou-se que 23,8\% (Paulo Freire), 12\% (Cachoeirinha) e $33 \%$ (Cajueiro) dos produtores possuem ensino fundamental incompleto e 4,7\% (Paulo Freire) e 3\% (Cachoeirinha) ensino médio completo. Acredita-se que pessoas com menor grau de escolaridade tem maior dificuldade de aceitar novas tecnologias e assimilar novas informações relacionadas às práticas de manejo. Vicente (2004) ao verificar a eficiência econômica da agricultura, ressaltou a educação como fator que influencia e aumenta a eficiência na produção e na qualidade de vida da população.

Tabela 1. Grau de escolaridade do produtor/assentado dos assentamentos Paulo Freire, Cachoeirinha e Cajueiro Sergipe (período de Novembro de 2007 a Janeiro de 2008).

\begin{tabular}{cccc}
\hline Nível de escolaridade & Paulo Freire (\%) & Cachoeirinha (\%) & Cajueiro (\%) \\
\hline Analfabeto & 28,5 & 49 & 27 \\
Alfabetizado & 42,8 & 36 & 40 \\
Fundamental incompleto & 23,8 & 12 & 33 \\
Ensino médio completo & 4,7 & 3 & - \\
\hline
\end{tabular}

Fonte: Elaboração dos autores. 


\section{Situação e condições de moradia}

Quanto ao tipo de moradia dos assentados, observou-se que $100 \%$ dos produtores estudados possuem moradia própria, financiadas pelo INCRA (Instituto Nacional de Colonização e Reforma Agrária) via Banco do Nordeste e construídas de alvenaria, apresentando condições mínimas de conforto às famílias assentadas. $\mathrm{O}$ assentamento Cachoeirinha apresenta água tratada e encanada em $100 \%$ da sua totalidade por ser atendido pela DESO (Companhia do Saneamento de Sergipe). No assentamento Cajueiro não foi constatado água tratada, pois esta é proveniente do rio São Francisco, transportada via caminhão pipa, armazenada em cisternas, evidenciando que as residências não possuem água encanada monitorada pela DESO. No assentamento Paulo Freire, água tratada e encanada não existem, sendo a água para consumo humano proveniente da chuva e armazenada em cisternas ou no caso de falta de água, um carro pipa abastece o município.

É visto que a grande maioria dos produtores possui uma infraestrutura precária. As fossas estão presentes em apenas 60 (Cachoeirinha) e 69,7\% (Cajueiro) das moradias e por falta de saneamento básico não há rede de esgoto. No assentamento Paulo Freire 80,9\% das moradias apresenta fossa, porém o esgoto é a céu aberto. Com relação a energia elétrica todos os produtores foram beneficiados com o programa "Luz para todos" do governo federal.

\section{Tamanho das propriedades rurais (lotes)}

Foi observada uma área total de 66,2 ha. dos assentamentos Paulo Freire, Cachoeirinha e Cajueiro, dos quais 18,56 ha. eram áreas de pastagens constituídas principalmente de gramíneas como o capim buffel (Cenchrus ciliaris L.). O predomínio do cultivo do capim buffel deve-se ao fato do clima da região semiárida apresentar precipitações médias anuais em torno de $500 \mathrm{~mm}$, favorecendo-a por ser uma forrageira de baixa exigência hídrica. A área média de pastagem nativa representou um total de 29,62 ha. entre os assentamentos. A área de capineira por lote, formada por capim elefante (Pennisetum purpureum L.), foi medida apenas para os assentamentos Paulo Freire (1,0 ha) e Cachoeirinha (0,5 ha). A área média destinada para agricultura de sequeiro (palma, milho e feijão) correspondeu a um total de 16,95 ha. (Tabela 2).

Tabela 2. Caracterização da área total nos assentamentos Paulo Freire, Cachoeirinha e Cajueiro - Sergipe (período de Novembro de 2007 a Janeiro de 2008).

\begin{tabular}{cccc}
\hline Caracterização da área (ha) & Paulo Freire & Cachoeirinha & Cajueiro \\
\hline Área média das propriedades & 22,7 & 22 & 21,52 \\
Área com pastagens & 4,0 & 7,25 & 7,31 \\
Área com capineira & 1,0 & 0,5 & - \\
Área cultivada (milho, feijão e palma) & 7,0 & 6,4 & 3,55 \\
Área com pastagens nativa & 10,7 & 8,23 & 10,69 \\
\hline
\end{tabular}

Fonte: Elaboração dos autores.

\section{Atividades desenvolvidas e renda familiar}

A bovinocultura de leite representou a principal fonte de renda para os assentados pesquisados (Tabela 3). Isto se deve a localização geográfica dos assentamentos Paulo Freire, Cachoeirinha e Cajueiro, ou seja, na bacia leiteira do sertão do São Francisco em Sergipe. Segundo Ferreira et al. (2009), a bovinocultura de leite é de grande importância econômica e social para o semiárido brasileiro, principalmente na região Nordeste, por 
ser menos vulnerável à seca, quando comparada com outras explorações agrícolas, e se constituir num dos principais fatores de fixação do homem no campo e de geração de emprego e renda.

Tabela 3. Nível de participação das explorações agropecuárias na renda familiar nos assentamentos Paulo Freire, Cachoeirinha e Cajueiro - Sergipe (período de Novembro de 2007 a Janeiro de 2008).

\begin{tabular}{cccc}
\hline Atividades desenvolvidas & Paulo Freire (\%) & Cachoeirinha (\%) & Cajueiro (\%) \\
\hline Bovinocultura de leite & 59,5 & 58 & 67,1 \\
Bovinocultura de corte & - & - & 1,3 \\
Ovinocultura & 1,4 & 5 & 1,2 \\
Agricultura sequeiro & 17,3 & 9 & 28,4 \\
Outras & 21,7 & 28 & 17 \\
\hline
\end{tabular}

Fonte: Elaboração dos autores.

Além da atividade de bovinocultura de leite são desenvolvidas nos assentamentos Paulo Freire, Cachoeirinha e Cajueiro a ovinocultura; a agricultura de sequeiro, na qual faz parte dos insumos por eles consumidos durante quase todo ano; e a bovinocultura de corte realizada apenas no assentamento Cajueiro. Outras atividades realizadas representam uma média de $22,2 \%$ de participação na renda familiar dos assentamentos (Tabela 3 ).

\section{Caracterização do rebanho}

Emrelaçãoà composição genética dorebanho, nos três assentamentos estudados foi constatado que os animais são provenientes de cruzamento entre gado Europeu (Holandês) e Indiano (Gir e/ou Guzerá), ou seja, animais mestiços com diferentes composições genéticas, refletindo na baixa produtividade por não ter potencial para produção de leite. Holanda Junior e Campos (2003) encontraram resultado semelhante no município de Quixeramobim, onde predominou (80\%) o rebanho bovino formado por animais mestiços Holandês/Zebu. Leite et al. (2004) também verificaram prevalência, em propriedades no Estado da Paraíba, de animais mestiços (87\%) para a exploração leiteira por serem mais adaptados às características da região. Monteiro et al. (2007) constataram predominância de animais mestiços em $95,1 \%$ das propriedades avaliadas no agreste do estado de Pernambuco.

No Brasil, os sistemas de produção de leite baseiam-se, em sua maioria, em animais da raça Holandesa e seus cruzamentos com outras raças, principalmente as de origem zebuína, tais como o Gir Leiteiro e o Guzerá (RENNÓ et al., 2002). Além disso, o predomínio de animais mestiços pode ser justificado pela opção dos produtores locais em utilizarem animais mais rústicos e resistentes para os diversos problemas encontrados na região, como o clima e as infestações parasitárias (AZEVEDO et al., 2011). Outra explicação é o baixo poder aquisitivo dos produtores dos assentamentos, impossibilitando-os de possuírem animais puros de raça europeia especializada, uma vez que resultariam em elevado gasto para manter tais animais, sendo que estes dificilmente se adaptariam as condições ambientais da região semiárida.

O rebanho leiteiro pertencente aos três assentamentos é composto por 664 cabeças, apresentando uma taxa média de $64,66 \%$ de vacas em lactação e de 35,33\% de vacas secas e /ou prenhes do total do rebanho.

Quanto à idade da primeira cobertura, observouse nos assentamentos Paulo Freire, Cachoeirinha e Cajueiro que 52; 42 e 97\%, respectivamente, das novilhas são cobertas entre 20 e 24 meses de idade, contra 4,$8 ; 10$ e $3 \%$, entre 31 a 36 meses de 
idade. Somente para os assentamentos Paulo Freire e Cachoeirinha observaram-se percentuais de 38 e $48 \%$ entre 25 a 30 meses de idade. Como o rebanho é predominantemente mestiço (zebu x holandês) esse intervalo está dentro das médias dos índices zootécnicos. No geral as novilhas são todas cobertas pelo sistema de monta natural sem controle.

Quanto ao manejo alimentar do rebanho, observase que o sistema de produção predominante nos três assentamentos estudados é o semi-intensivo, no qual na época da seca (verão), o rebanho é alimentado basicamente com palma forrageira, farelo de trigo, farelo de soja, rolão de milho e caroço de algodão. Os produtores não utilizam forragens conservadas, tais como feno, silagem ou até mesmo leguminosas como a gliricídia (Gliricídia sepium) e a leucina (Leucaena leucocephala) para alimentação do rebanho leiteiro. Lima et al. (2009) comentam que a produção de forragem conservada para uso na época da estiagem é de grande importância, principalmente na região semiárida, para manutenção dos rebanhos.

Nos três assentamentos estudados, os índices de controle sanitário do rebanho apresentaram 100 $\%$ de aplicação de vacinas, principalmente contra a febre aftosa por ser obrigatório e fiscalizado pela EMDAGRO (Empresa de Desenvolvimento Agropecuário de Sergipe). O controle profilático de enfermidades como diarreia, miiase, mastite, entre outras corresponderam a 97\% (Cajueiro), 95\% (Paulo Freire) e 66,6\% (Cachoeirinha). O controle de ectoparasitas e endoparasitas como carrapato e verminose é realizado por $100 \%$ dos assentados dos três assentamentos. Azevedo et al. (2011) em estudo para caracterizar propriedades leiteiras situadas na mesorregião do norte de Minas Gerais, observaram vermifugações empregadas em $74,5 \%$ das propriedades e carrapaticidas utilizados em 93,6\% das propriedades. Para Holanda Júnior e Campos (2003), a sanidade dos animais é de fundamental importância para o desenvolvimento da atividade leiteira, pois qualquer esforço para melhoria da alimentação e manejo do rebanho não será efetivo caso os animais não apresentem um estado de saúde satisfatório.

De acordo com a tabela 4, os animais dos assentamentos Paulo Freire, Cachoerinha e Cajueiro apresentaram produções médias de leite em torno de 5,8 litros/vaca/dia, valor acima da média nacional que é cerca de 4 litros/vaca/dia (IBGE, 2010). Esta baixa produção demonstra potencial genético limitado destes animais para este fim associado à falta de um planejamento nutricional na época seca. Foi registrada produção total, para os três assentamentos, de 2499 litros de leite/dia, destes, 2310 litros foram comercializados e o restante consumido pela própria família. As médias de produção de leite diária comercializada por produtor foram de 35,4 (Paulo Freire); 22,27 (Cachoeirinha) e 28,9 (Cajueiro) litros.

Os rebanhos bovinos dos assentamentos Cachoeirinha, Paulo Freire e Cajueiro eram ordenhados apenas uma vez por dia $(94 ; 100$ e $79 \%$ ). Essa ordenha é manual com a presença do bezerro ao pé e feita pela manhã. Os $6 \%$ (Cachoeirinha) e 21\% (Cajueiro) restantes eram ordenhados duas vezes ao dia, sendo o leite vendido para atravessadores no período da tarde. De acordo com os produtores locais, a predominância de uma única ordenha ao dia deve-se ao limitado potencial genético dos animais gerando uma baixa produção de leite por vaca associado à falta de um resfriador de leite coletivo nos assentamentos. 
Tabela 4. Valores médios de produção de leite e quantidades comercializadas e consumidas nos assentamentos Paulo Freire, Cachoeirinha e Cajueiro - Sergipe (período de Novembro de 2007 a Janeiro de 2008).

\begin{tabular}{cccc}
\hline & Paulo Freire & Cachoeirinha & Cajueiro \\
\cline { 2 - 4 } Produção média diária de leite por vaca (litros) & 5,4 & 5,5 & 6,5 \\
Produção total diária (litros) & 744 & 739 & 1016 \\
Quantidade comercializada (litros) & 683 & 673 & 954 \\
Quantidade consumida pela própria família (litros) & 61 & 66 & 62 \\
Produção de leite diária por produtor (litros) & 35,4 & 22,27 & 28,9 \\
\hline
\end{tabular}

Fonte: Elaboração dos autores.

O período de lactação do rebanho leiteiro dos assentamentos Cachoeirinha, Paulo Freire e Cajueiro tiveram duração de até 180 dias (52; 42,8 e $27 \%)$, de 181 a 240 dias $(45 ; 57,2$ e $58 \%)$ e acima de 240 dias de lactação apenas 3\% (Cachoeirinha) e $15 \%$ (Cajueiro) do rebanho. A predominância dos períodos de lactação entre 180 a 240 dias, possivelmente é devido ao rebanho ser mestiço, com baixa persistência de lactação associado às condições climáticas da região na época.

\section{Custo de produção e valor médio recebido por litro} de leite

$\mathrm{Na}$ época de realização desta pesquisa (verão), a região apresentava escassez de alimento para os animais. $\mathrm{O}$ custo de produção do leite foi elevado devido a gastos com ração balanceada e à compra de palma forrageira para alimentação do rebanho. Para se chegar ao custo de produção do leite estimado, levaram-se em consideração os preços dos insumos (soja, caroço de algodão, farelo de trigo e rolão de milho) e da palma forrageira utilizados na alimentação do rebanho bovino, além de se considerar a diária da mão-de-obra do produtor ( $\mathrm{R} \$$ $15,00)$, pois ao se dedicar exclusivamente aos seus trabalhos diários no manejo do rebanho, este era impossibilitado de realizar atividades braçais para terceiros.

Os consumos médios diários de ração balanceada pelos rebanhos dos assentamentos Paulo Freire, Cachoeirinha e Cajueiro e custos de produção encontram-se na Tabela 5. Observou-se custo médio por kg de ração no valor de $\mathrm{R} \$ 0,85 ; \mathrm{R} \$ 0,74$ e $\mathrm{R} \$ 0,77$ para os respectivos assentamentos, gerando custos para produção de um litro de leite de $\mathrm{R} \$ 1,42 ; \mathrm{R} \$$ 1,44 e $\mathrm{R} \$ 1,19$. Contudo, o valor recebido por litro de leite comercializado diariamente estava na faixa de $\mathrm{R} \$ 0,53$ tornando o sistema economicamente inviável para os produtores estudados.

Tabela 5. Consumo de alimento e custo de produção nos assentamentos Paulo Freire, Cachoeirinha e Cajueiro Sergipe (período de Novembro de 2007 a Janeiro de 2008).

\begin{tabular}{cccc}
\hline Item & Paulo Freire & Cachoeirinha & Cajueiro \\
\hline Média consumo de palma/dia/vaca $(\mathrm{kg})$ & 19,449 & 23,370 & 24,840 \\
Média de consumo de ração balanceada/dia/vaca $(\mathrm{kg})$ & 3,188 & 3,190 & 3,28 \\
Custo médio kg de ração balanceada/dia/vaca $(\mathrm{R} \$)$ & 0,85 & 0,74 & 0,77 \\
Custo médio de produção de um litro de leite $(\mathrm{R} \$)$ & 1,42 & 1,44 & 1,19 \\
Valor médio recebido por litro de leite $(\mathrm{R} \$)$ & 0,54 & 0,53 & 0,52 \\
\hline
\end{tabular}

Fonte: Elaboração dos autores. 
Diante da baixa produção de leite diária, a receita da venda do leite é muito pouca para ser dividida com o produtor e alimentação para os animais que não estão produzindo. O elevado custo de produção possivelmente é consequência da falta de assistência técnica e do rebanho ser composto por animais de baixo potencial genético para a produção de leite. Já a variabilidade dos preços pode ser determinada pela estação do ano e pela forma e local de comercialização. De forma geral, o preço recebido por litro de leite durante a estação seca tende a ser maior do que durante a estação chuvosa, devido a queda da produção e consequente diminuição da oferta do produto, causada pricinpalmente pela redução da disponibilidade das pastagens e de água, encarecendo o processo produtivo através do uso de maior quantidade de concentrado para compensar a falta e/ou a baixa qualidade das pastagens (HOLANDA JUNIOR; CAMPOS, 2003).
Principais problemas enfrentados para o desenvolvimento da bovinocultura leiteira local

Os problemas enfrentados pelos produtores de leite, nos três assentamentos estudados, apresentaram percentuais bastante elevados que contribuíram de forma negativa para um bom desenvolvimento desta atividade. Na Tabela 6 encontram-se os principais problemas observados. Verificou-se altos preços dos insumos utilizados na alimentação dos rebanhos dos assentamentos, elevando o custo de produção do leite e, muitas das vezes, inviabilizando a exploração da bovinocultura leiteira. Além disso, 61,9\% (Paulo Freire) e 12\% (Cachoeirinha) dos produtores alegaram o preço baixo do produto (leite) vendido como mais um problema enfrentado na bovinocultura local, embora a realidade da época demonstre que o leite estava com bons níveis de preços.

Tabela 6. Problemas enfrentados na atividade leiteira nas regiões dos assentamentos Paulo Freire, Cachoeirinha e Cajueiro - Sergipe (período de Novembro de 2007 a Janeiro de 2008).

\begin{tabular}{cccc}
\hline Principais problemas & Paulo Freire (\%) & Cachoeirinha (\%) & Cajueiro (\%) \\
\hline Preço alto dos insumos & 71,4 & 90 & 100 \\
Preço baixo dos produtos & 61,9 & 12 & - \\
Falta de financiamento & 33,33 & - & 100 \\
Falta de informação & 28,57 & 81 & 48 \\
Dificuldade de acesso à tecnologia e assistência & 23,8 & 90 & 84,8 \\
técnica & 19,04 & 21 & 72,7 \\
Pouca ou falta de mão de obra especializada & 19,04 & - & - \\
Outros & &
\end{tabular}

Fonte: Elaboração dos autores.

A falta de mão de obra especializada foi observado em 19,04\% (Paulo Freire); 21\% (Cachoeirinha) e $72,7 \%$ (Cajueiro) e estão ligados ao grau de escolaridade dos produtores, ou seja, apesar do número significativo de produtores alfabetizados, a grande maioria somente sabe ler e escrever o próprio nome. Isso dificulta o entendimento para empregar novas técnicas tais como: melhor manejo do rebanho em época seca e redução de gastos com a alimentação.
Com relação a dificuldade de acesso a tecnologia e assistência técnica, foram observados percentuais de 23,8 (Paulo Freire); 90 (Cachoeirinha) e $84,8 \%$ (Cajueiro). Segundo os produtores dos assentamentos estudados, os técnicos contratados pelo MST e INCRA chegavam até a sede da associação, não indo diretamente aos lotes. Essa falta de assistência técnica aos assentamentos pode ser vista como o principal fator que leva aos baixos índices produtivos do rebanho bovino nos 
assentamentos, ou seja, o produtor passa a agir ou manejar o seu rebanho por conta própria.

A falta de informações foi detectado principalmente no assentamento Cachoeirinha. Os criadores justificaram não produzirem melhor por não possuírem informações necessárias, confirmando a falta de assistência técnica nos assentamentos. A falta de financiamento foi alegada apenas pelos produtores dos assentamentos Paulo Freire e Cajueiro, apresentando percentuais de 33,33 e $100 \%$ (Tabela 6). Isto é explicado por esses produtores estarem inadimplentes junto às agências financiadoras e com isso ficaram restritos a obter novos financiamentos junto aos bancos. Estes alegaram que apenas na época quando foram assentados é que receberam financiamentos de projetos como PRONAF (Programa Nacional de Fortalecimento da Agricultura Familiar) e outros progamas do governo federal como o INCRA.

\section{Conclusão}

A pecuária leiteira desenvolvida nos assentamentos Paulo Freire, Cachoeirinha e Cajueiro passa por sérias dificuldades, tais como: ausência da assistência técnica local, dificuldade de acesso à tecnologia, alto índice de analfabetismo e elevado custo para a produção de leite. Faz-se necessário o fomento de pesquisas e alternativas para melhorar a produtividade e a sustentabilidade de produtores com essas condições de criação e que o MST invista principalmente em contratação de técnicos especializados para prestarem assistência técnica e educação aos assentados e consequentemente, promover uma aceleração do desenvolvimento dos assentamentos.

\section{Referências}

AZEVEDO, R. A. de; FELIX, T. M.; PIRES JÚNIOR, O. S.; ALMEIDA, A. C. de; DUARTE, E. R. Perfil de propriedades leiteiras ou com produção mista no norte de minas gerais. Revista Caatinga, Mossoró, v. 24, n. 1, p. 153-159, 2011.
FERNANDES, T. A. G.; LIMA, J. E. Uso de análise multivariada para identificação de sistemas de produção. Pesquisa Agropecuária Brasileira, Brasília, v. 26, n. 10, p. 1823-1836, 1991.

FERREIRA, M. A.; SILVA, F. M. da; BISPO, S. V.; AZEVEDO, M. de. Estratégias na suplementação de vacas leiteiras no semi-árido do Brasil. Revista Brasileira de Zootecnia, Viçosa, MG, v. 38, p. 322-329, 2009. Número Especial.

HOLANDA JUNIOR, F. I.; CAMPOS, R. T. Análise técnico-econômica da pecuária leiteira no Município de Quixeramobim - Estado do Ceará. Revista Econômica do Nordeste, Fortaleza, v. 34, n. 4, p. 621-646, 2003.

INSTITUTO BRASILEIRO DE GEOGRAFIA E ESTATÍSTICA - IBGE. Sintese de indicadores sociais. Uma análise das condições de vida da população brasileira. Rio de Janeiro: IBGE, 2009. 252 p.

. Produção da pecuária municipal. Rio de Janeiro: IBGE, v. 38, p. 1-65, 2010.

MINISTÉRIO DO DESENVOLVIMENTO AGRÁRIO - MDA. Instituto Nacional de Colonização e Reforma Agrária. Relatório 0227. 2012. Disponível em: <http:// www.mda.gov.br/portal/>. Acesso em: 18 maio 2013.

MONTEIRO, A. A.; TAMANINI, R.; SILVA, L. C. C. da; MATTOS, M. R. de; MAGNANI, D. F.; D'OVIDIO, L.; NERO, L. A.; BARROS, M. A. F.; PIRES, E. M. F.; PAQUEREAU, B. P. D.; BELOTI, V. Características da produção leiteira da região do agreste do estado de Pernambuco, Brasil. Semina: Ciências Agrárias, Londrina, v. 28, n. 4, p. 665-674, 2007.

LEITE, R. H. M.; LAGE, A. P.; JAYME, V. S.; MODENA, C. M. Perfil produtivo-sanitário de propriedades produtoras de bovinos do Estado da Paraíba, Brasil, 2000. Ciência Animal Brasileira, Goiânia, v. 5, n. 4, p. 199-209, 2004.

LIMA, P. O.; DUARTE, L. S.; SOUZA, A. Z. B.; AQUINO, T. M. F.; OLIVEIRA, C. S. Perfil dos produtores rurais do município de Quixeramobim no Estado do Ceará. Revista Caatinga, Mossoró, v. 22, n. 4, p. 255-259, 2009.

RENNÓ, F. P.; PEREIRA, J. C.; ARAÚJO, C. V.; TORRES, R. A.; RODRIGUES, M. T.; RENNÓ, L. N.; OLIVEIRA, R. F. M. de; KAISER, F. R. Aspectos produtivos da raça pardo-suíça no Brasil. Fatores de ajustamento, produção de leite e gordura e parâmetros genéticos. Revista Brasileira de Zootecnia, Viçosa, MG, v. 31, n. 5, p. 2043-2054, 2002.

SANTOS, P. L. S.; AZEVEDO, E. O. Perfil socioeconômico de produtores de leite do estado da 
Paraíba, Brasil. Revista Caatinga, Mossoró, v. 22, n. 4, p. 260-267, 2009.

SERVIÇO DE APOIO ÀS MICRO E PEQUENAS EMPRESAS DO PIAUÍ - SEBRAE/PI. Diagnóstico sócio-econômico das Bacias leiteiras de Parnaíba-PI e Teresina-PI. Serviço Nacional de Aprendizagem Rural - Administração Regional do Piauí. Teresina: SEBRAE/ PI, 2005. $36 \mathrm{p}$.
SISTEMA DE INFORMAÇÕES SOBRE RECURSOS HÍDRICOS DO ESTADO DE SERGIPE - SIRHSE. Elaboração do plano estadual de recursos hídricos. Relatório Síntese da Fase A. Sergipe: SEMARH, 2010. $72 \mathrm{p}$.

VICENTE, R. J. Economic efficiency of agricultural production in Brazil. Revista de Economia e Sociologia Rural, Rio de Janeiro, v. 42, n. 2, p. 201-222, 2004. 